\title{
Structural design of soldering station chain conveyor working positions
}

\author{
Miroslav Blatnický ${ }^{1}$, Ján Dižo ${ }^{1, *}$, Mária Blatnická $^{2}$ \\ ${ }^{1}$ Faculty of Mechanical Engineering, University of Žilina, Department of Transport and Handling \\ Machines, Univerzitná 8215/1, 01026 Žilina, Slovak Republic \\ ${ }^{2}$ Faculty of Mechanical engineering, University of Žilina, Department of Applied Mechanics, \\ Univerzitná 8215/1, 01026 Žilina, Slovak Republic
}

\begin{abstract}
The paper deals with design of the support and guide of the conveyor chain links, the individual working positions of the handling mechanism for the conveyor line, i.e. positions of manual loading of components on the line and automatic soldering of the component. The entire design will serve as an input for the dimensional calculation of the propulsion engine of the proposed conveyor line in order to enable the production of a real functional prototype.
\end{abstract}

Keywords: chain conveyor, structural design, 3D modelling, soldering station

\section{Introduction}

An important role of engineers is to analyse used and newly designed workflows to find the optimal way to perform the operation.

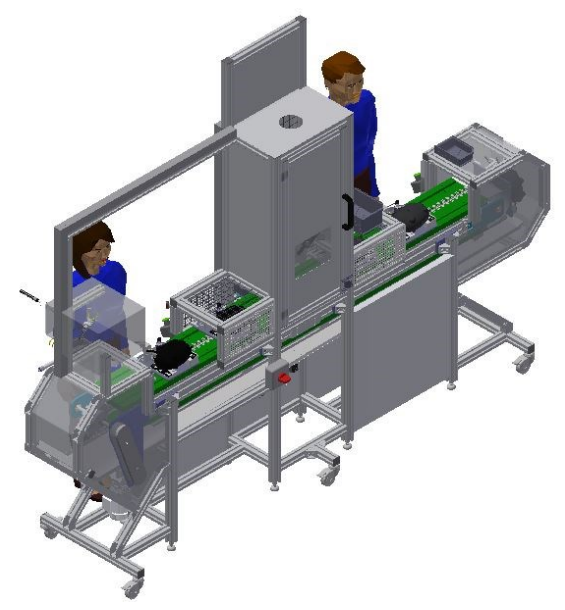

Fig. 1. General view of the proposed soldering station

\footnotetext{
*Corresponding author: jan.dizo@fstroj.uniza.sk

Reviewers: Jan Krmela, Ján Vavro Jr.
} 
The best workflow is generally considered to be the one that minimizes costs for performance, which can be achieved by mechanization. Mechanization is an important means of increasing productivity, quality and competitiveness of production. It is necessary to know and understand the physical dependence of the performed operations for the successful implementation of mechanization. The operations are carried out by transferring mechanical, electrical, pneumatic or hydraulic power [1]. The effort is to make the individual workings as short and simple as possible to make them easy to learn while demanding a minimum of human effort. Mechanism greatly relieves man from heavy physical work, for example, in a hazardous or harmful environment. Such a mechanism is also the proposed chain conveyor of the soldering station (Fig. 1), which greatly facilitates the handling process with great operability, and with the condition of minimal production costs we achieve the most cost-effective ratio.

\section{Supporting and guiding chain links}

Chain conveyors, as one of the types of transport and handling equipment, interfere with their activities in all areas of the national economy. By doing so, they make work easier and increase the efficiency of production. It belongs to a group of conveyors with a towing element and we can define them as transport equipment that fulfils the function of the towing element by one or more closed chains circulating around the end sprockets. These conveyors are used in various engineering branches. There are two types of the conveyor support and guide, namely sliding or rolling, and its task is to absorb the gravitational forces from the belt and the conveyed material. These forces used to be large and have an impact on the conveyor movement power losses and therefore the sliding guide is only recommended for short, low-capacity conveyors. Since the conveyor will have a total length of about $3 \mathrm{~m}$, the sliding guide of the belt (Fig. 2) has been selected during construction.

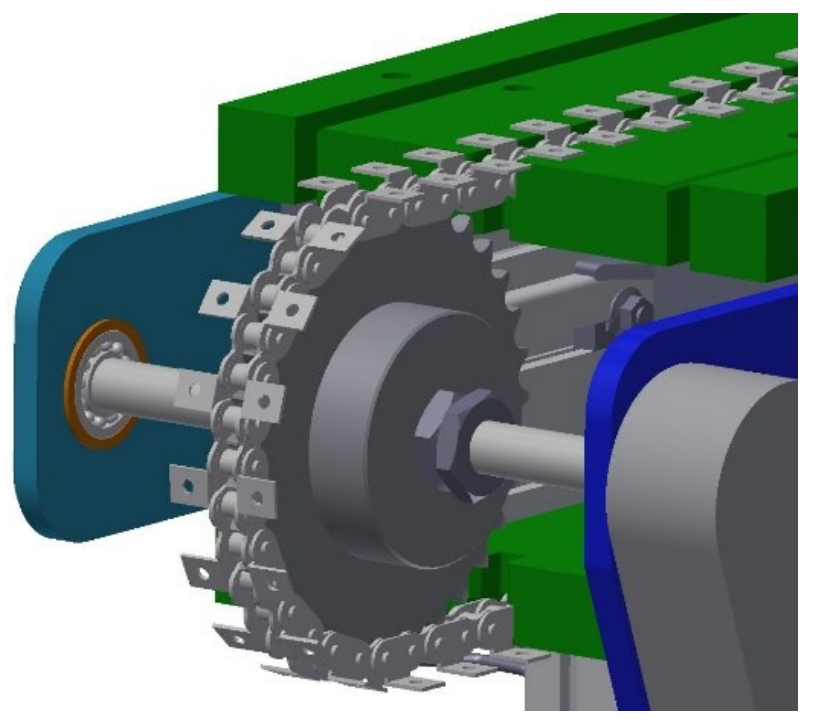

Fig. 2. Detail of the chain guide design

Chains can be led in either chain metal guides or plastic guides that are sufficiently resistant to wear and also reduce chain wear [2]. In view of this, plastic chains made of POM have been chosen that are designed so that the chain is guided in plastic. 


\section{Design of the position no. 1}

At position no. 1 (Fig. 3) operator manually loads the compressor into the pallet bed and bends the compressor hose to the position according to the jig.

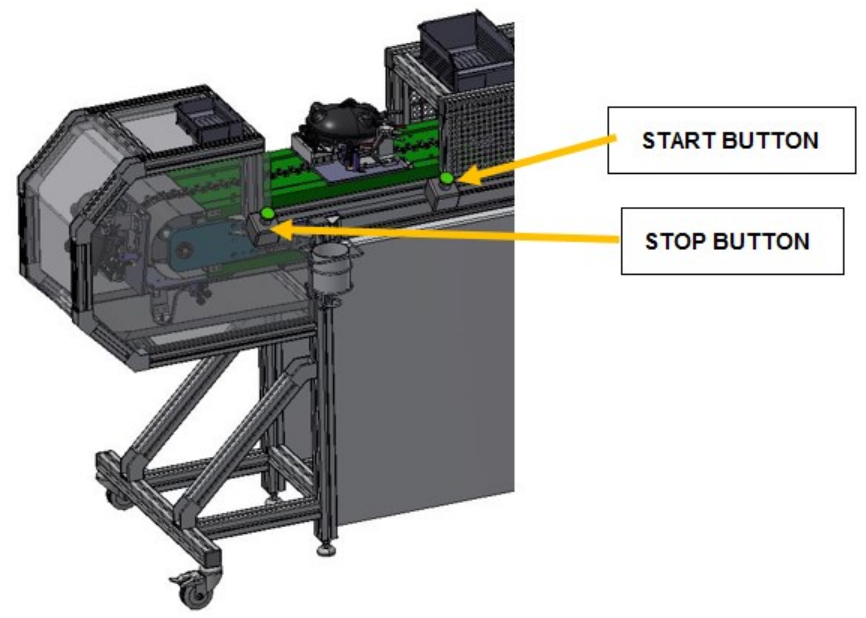

Fig. 3. Operator's view of work position no. 1

They put on the solder and the outlet pipe, then spread colophony on the joint and press the green OK button (start). The palette moves automatically by one position to position no. 2 , where automatic soldering is carried out by burner.

\section{Design of the position no. 2}

Design of the soldering position (position 2) was one of the more complex designs of this device. It was necessary to design a vertical movement of the soldering burner with adjustable stops at both positions and the mechanism of the lock off / lock in of the outlet pipe in the pallet, subsequent fixation of the burner on the sliding mechanism, the positioning of the auxiliary burner for ignition of the main (welding) burner and the locking mechanism for stopping the pallet in the desired position.
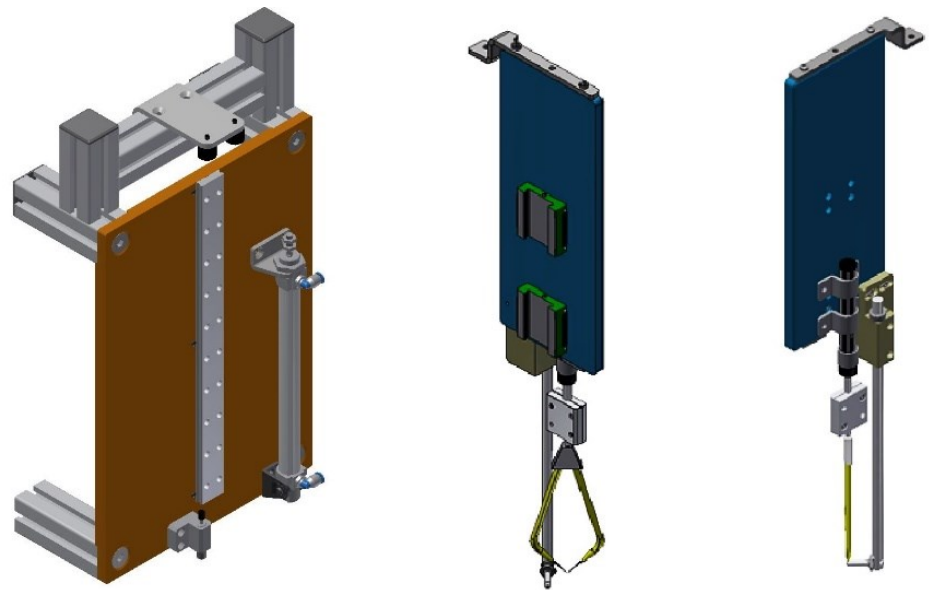

Fig. 4. Linear line mechanism design (left) and proposed sliding mechanism (right) 
When designing the sliding mechanism, it was necessary to choose such a pneumatic cylinder $[3,4,5]$ to be able to lift the mechanism that is being moved in the linear guide (two carts on the rail). A cylinder from Festo (www.festo.com) with the designation 0822033208 was configured. The cylinder configuration was dependent on its desired lift.

For this mechanism, the rail with designation of WEH17CA has been designed to provide accurate guidance in the vertical direction. The rail is mounted on a rigid board (orange plate Fig. 4 left) along with the designed $45 \times 45 \mathrm{~mm}$ (Bosch Rexroth) profile $[5,6,7]$ and they both are mounted on the profile frame of the conveyor. On the sliding mechanism, two carts (HIWIN WET17CA) are bolted from the bottom by 4 screws on the sliding plate (blue plate in Fig. 4 right), which assures movement towards and away from of the soldering (welding) device on the rail $[8,9,10]$. At the end positions, a stop and a pneumatic damper is used to cushion the impact when moving the pneumatic cylinder.
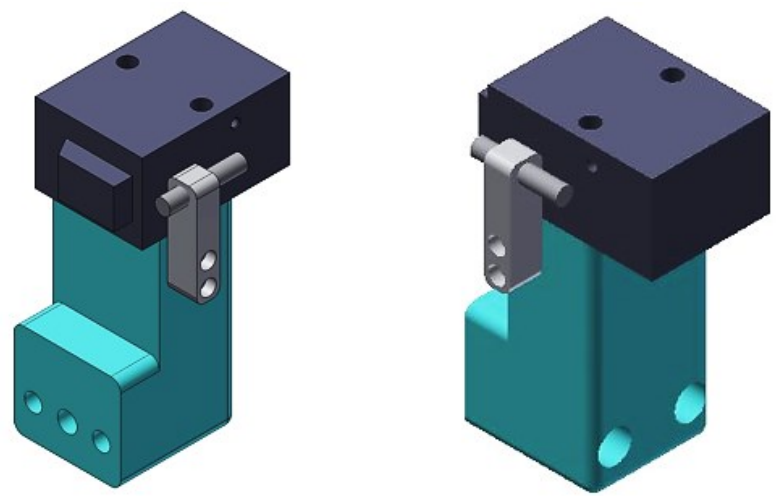

Fig. 5. Pallet stopping mechanism (position no. 2)

At position no. 2 it was also necessary to solve the pallet stop in the desired position. A stop mechanism has been designed for this purpose (Fig. 5). It consists of a pneumatic stopper, a holder to which the stopper is screwed by two screws and two pins and an inductive sensor which is screwed from the side of the holder. The sensor serves to indicate the presence of the pallet at position no. 2 .
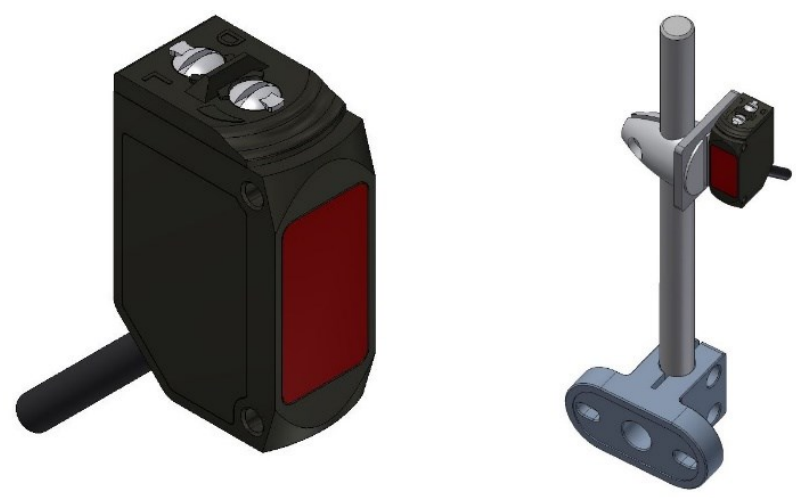

Fig. 6. Optical sensor (left) with designed holder (right)

Furthermore, it was necessary to sense the presence of the compressor on the pallet at this position. The reason was to avoid soldering (welding) in case an empty pallet without a compressor (component) would arrive at the workstation. The optical sensor $06 \mathrm{H}-300$ SICK (Fig. 6) was used for this purpose. It was necessary to design a holder that would 
allow the sensor to be set in any direction and at the same time make it easy to produce [11].

The proposed holder consists of two purchased BAM parts, a stainless steel rod of $12 \mathrm{~mm}$ diameter and a holder with sensor screwed on an adjustable joint (Fig. 6). The holder is bolted by two screws on the support profile of the conveyor (Fig. 6). Since there is a door in the workspace at position no. 2, it was necessary to prevent any intrusion (hand, various hand gripped objects) into the working space during the operation (soldering). The SICK I200-EO323 automatic electric lock was used for security (Fig. 7).
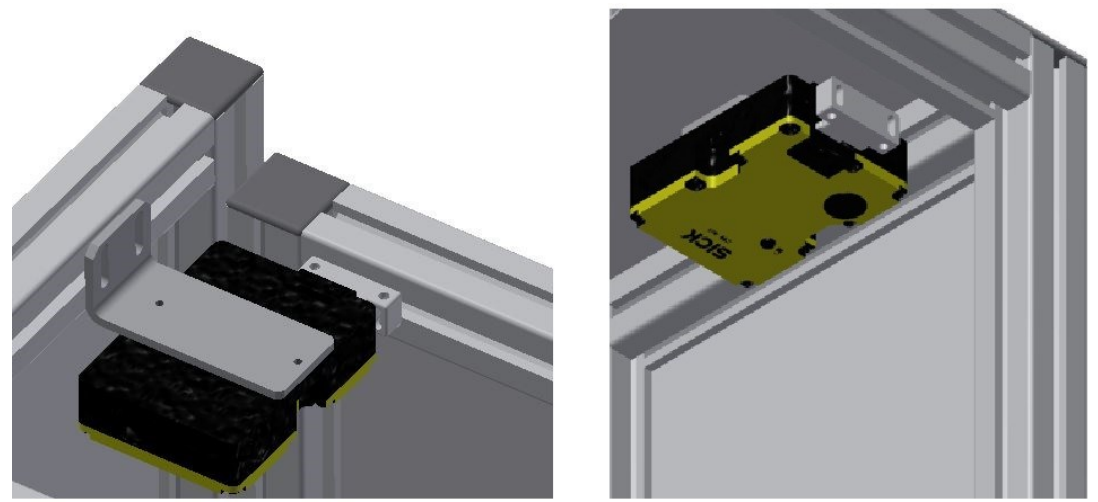

Fig. 7. Optical sensor (left) with designed holder (right)

To bolt the lock it was designed a holder for mounting the main part to the conveyor frame. The second part (so-called fork) was mounted to the door frame. This lock serves to automatically switch off the pneumatic and electrical supply to the designed device for safety reasons.

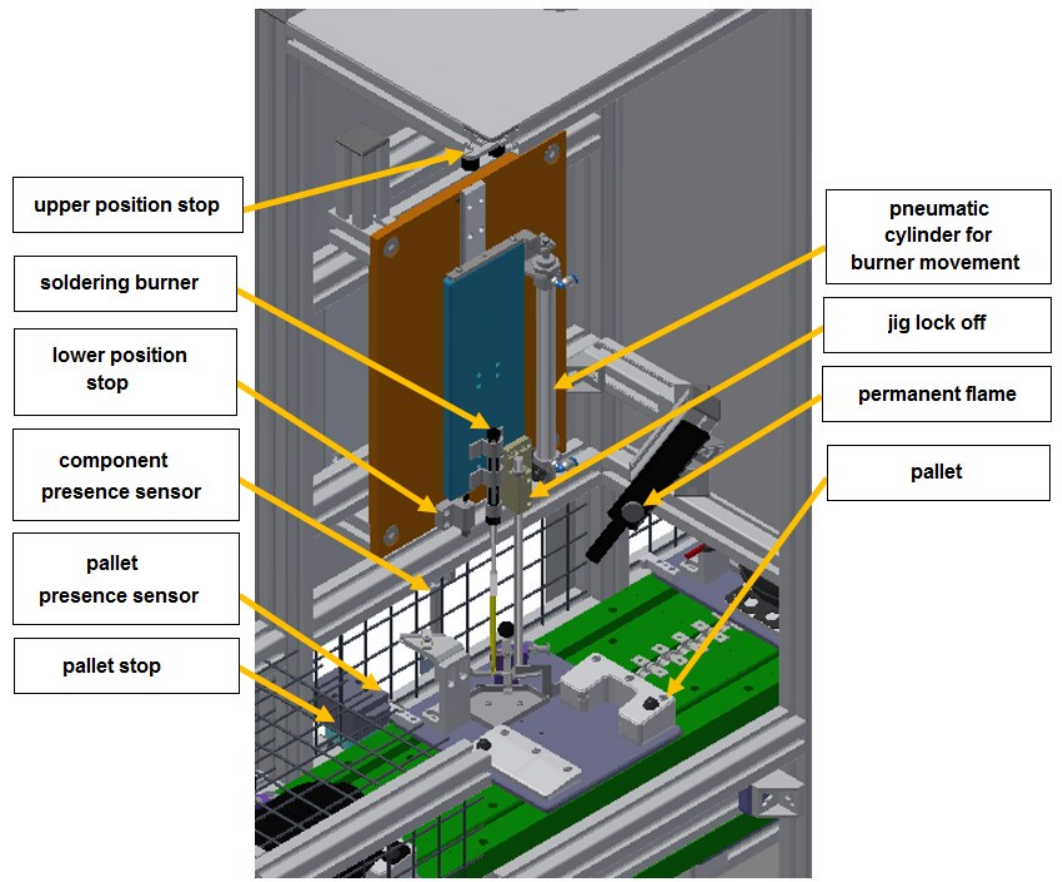

Fig. 8. View of working position no. 2 
Working position no. 2 (Fig. 8) is automatic. In this position, the outlet pipe is soldered. The pallet comes to the stop and the presence of the piece on the pallet is sensed. The main burner activates and using the pneumatic cylinder, the burner is moved to the working position where the outlet pipe is soldered. After soldering, the burner switches off and returns to the base position. Another task in designing the device was to design a placement for an electrical switchboard [12-14]. It is located under the conveyor structure at position no. 1. The operating panel, which serves as a software for managing and controlling the entire operating line, was placed in the frame of the transport line at position no. 2 from the operator's side, where the buttons for starting and stopping the machine are located. Another problem was the location of a pneumatic block, which serves to control the pneumatic components used on the device.

\section{Conclusion}

The aim of the article was to create a design of the first two of the three working positions of the automatic soldering station conveyor (Fig. 9), namely the first manual position where the components are loaded into the jigs and the second fully automated welding position of the components.

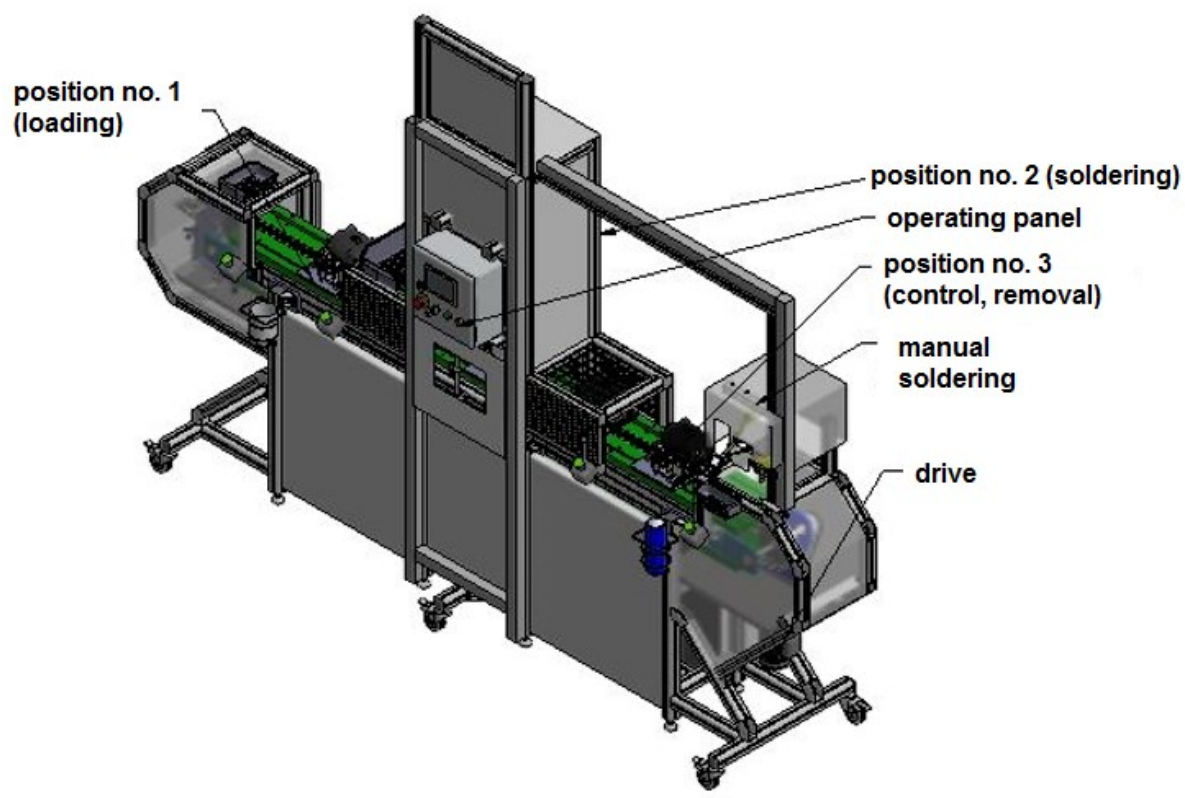

Fig. 9. Overview of the proposed workstation

We can say that this goal has been fulfilled. In the next step of solving this problem, it will be necessary to design a third manual position for checking the tightness of the joint and to perform the dimensional calculation of the drive electric motor. After this step, the prototype of the compressor discharge line soldering station of the compressor can be used to bring the functional device into operation. 
This article was supported by the project VEGA 1/0927/15 "Research of the use of alternative fuels and hybrid drives on traction vehicles with aim to reduce fuel consumption and air pollutants production".

The work was supported by the Cultural and Educational Grant Agency of the Ministry of Education of the Slovak Republic in project No. KEGA 077ŽU-4/2017: Modernization of the Vehicles and engines study program.

This publication is the result of the project implementation: Modern methods of teaching control and diagnostic systems of engine vehicles ITMS 26110230107 supported by the Operational Programme Education funded by the ESF.

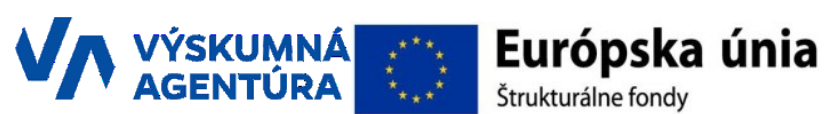

\section{References}

1. L. Kašiar, P. Zvolenský, D. Barta, L. Bavlna, M. Mikolajčík, P. Drożdziel, Diagnostics of electric motor of locomotive series 757. Diagnostyka 3, 95-101 (2016)

2. J. Gerlici, T. Lack, Railway wheel and rail head profiles development based on the geometric characteristics shapes. Wear 1-2, 246-258 (2011)

3. J. Harušinec, M. Maňurová, A. Suchánek, Optimization of a brake unit in terms of control range. Manufacturing Technology 5, 917-923 (2016)

4. J. Gerlici, T. Lack, Rail vehicles brake components test bench utilisation. Applied mechanics and materials 486, 379-386 (2014)

5. J. Gerlici, T. Lack, Contact geometry influence on the rail/wheel surface stress distribution. Procedia Engineering 1, 2249-2257 (2010)

6. J. Gerlici, T. Lack, J. Harušinec, Realistic simulation of railway operation on the RAILBCOT test stand. Applied mechanics and materials 486, 387-395 (2014)

7. J. Gerlici, T. Lack, J. Harušinec, The test stand load modulus implementation for the realistic railway operation in the laboratory conditions. Manufacturing Technology 4 , 444-4495 (2013)

8. J. Gerlici, T. Lack, Modified HHT method for vehicle vibration analysis in time domain utilisation. Applied mechanics and materials 486, 396-405 (2014)

9. T. Lack, J. Gerlici, A modified strip method to speed up the calculation of tangential stress between wheel and rail. Applied mechanics and materials 486, 371-378 (2014)

10. T. Lack, J. Gerlici, A modified strip method to speed up the calculation of normal stress between wheel and rail. Applied mechanics and materials 486, 359-370 (2014)

11. J. Skočilas, B. Skočilasová, J. Soukup, Determination of the rheological properties of thin plate under transient vibration. Latin American Journal Of Solids And Structures 1, 189-195 (2013)

12. J. Zapoměl, V. Dekýš, P. Ferfecki, A. Sapietová, M. Sága, M. Žmindák, Identification of material damping of a carbon composite bar and study of its effect on attenuation of its transient lateral vibrations. International journal of applied mechanics 7/6, $18 \mathrm{p}$. (2015)

13. M. Sága, M. Vaško, P. Kopas, L. Jakubovičová, Application of Karray-Bouc hysteretic model for cumulative damage calculation using energy fatigue curve. Applied mechanics and materials 611, 32-39 (2014) 
14. J. Gerlici, I. A. Shedchikova, I. V. Nikitchenko, J. A. Romanchenko, Investigation of influence of separator magnetic system configuration with permanent magnets on magnetic field distribution in working area. Electrical engineering \& electromechanics 2, 13-17 (2017) 